\title{
Potential for high transient doses due to accumulation and chemical zonation of long-lived radionuclides across the geosphere-biosphere interface
}

\author{
R.A. Kłos ${ }^{1}$, G. Shaw ${ }^{2}$, S. Xu ${ }^{3}$, B. Dverstorp ${ }^{3}$, M. Nordén ${ }^{3}$ and A. Wörman ${ }^{4}$ \\ ${ }^{1}$ Aleksandria Sciences, UK \\ ${ }^{2}$ University of Nottingham, UK \\ ${ }^{3}$ Swedish Radiation Safety \\ ${ }^{4}$ Authority (SSM), SE-171 16 Stockholm, Sweden, Royal Institute \\ of Technology (KTH), Sweden \\ e-mail: shulan.xu@ssm.se
}

\begin{abstract}
Planning for the disposal of spent nuclear fuel is at an advanced stage in several nations around the world. Licensing of the disposal facility requires correspondingly detailed assessment of the future performance of the facility. With increased site-specific detail available to the assessment, local characteristics play an increasingly important role in determining the potential radiological risk posed by releases to the biosphere. In this paper we go beyond existing reference biosphere models and investigate the potential for specific accumulation mechanisms. The implications for the modelling carried out in long timescale performance assessment are discussed.
\end{abstract}

\section{BACKGROUND}

Post-closure safety assessments for nuclear waste repositories (Performance Assessments, PAs) involve radioecological analysis of the release to the surface environment from an underground source(s). Models for PA applications have been under development for over thirty years. At early stages of a waste disposal programme generic modelling is appropriate; the international Reference Biospheres Methodology has been developed to construct stylised biospheres based on present-day biosphere analogues [1]. Traditionally, long-term safety assessments treat the geosphere and biosphere as distinct model domains, coupled only by the nuclide-specific biosphere dose conversion factor.

In more advanced disposal programmes, for example in Sweden, an integrated modelling approach has recently been developed [2] in which "landscape models", based on detailed site-specific data, are used to evaluate radionuclide accumulations in the biosphere, together with associated doses. In this approach land uplift induced by climate evolution (glaciation cycles) and a number of connected biosphere objects are considered. However, the coupling of geosphere and biosphere models remains a weak aspect and structures within ecosystem models are greatly simplified [3].

A transparent and credible dose assessment must demonstrate that all relevant features, processes and events have been handled appropriately in the assessment model. The focus on "landscape modelling" in contemporary assessments has overshadowed the need for suitably representative models of radionuclide transport in both the traditional biosphere objects and in deeper components of the geosphere-biosphere interface. Independent PA modelling carried out by SSM emphasises the internal dynamics of landscape objects. Once activity has reached the landscape drainage system, contaminants are lost fairly rapidly from the area around the release point. What biosphere accumulation does occur, takes place predominantly in the locality of the release [4] and the degree of accumulation depends on the nature of the ecosystem into which the release occurs [5]. Biosphere processes are inherently dispersive but some promote the concentration of contaminants in relatively small volumes. 


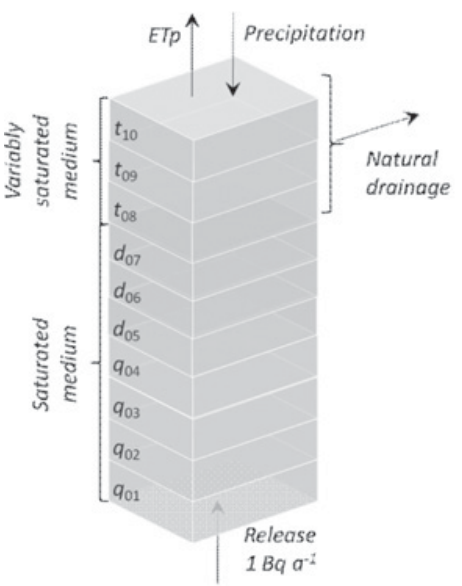

(a) Wetland column

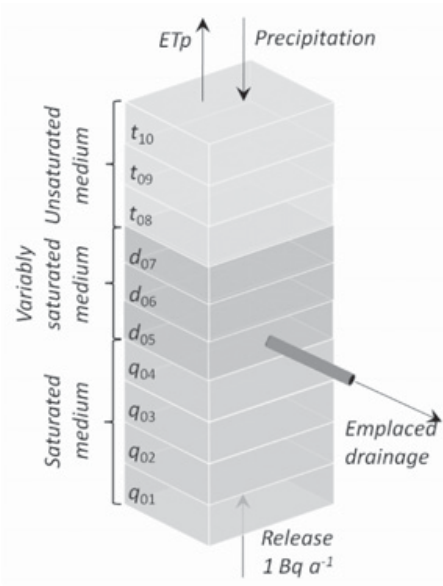

(b) Agricultural soil column

Figure 1. Structures of wetland and agricultural soil columns.

Two areas are of particular concern: 1) hydrogeochemical zonation causing concentration of contaminants in the accessible part of the surface environment, and, 2) accumulation during a period of limited human activity leading to higher exposures on subsequent change in land use. Concern about landscape object size (contributing to spatial dilution) has been discussed elsewhere [6]. These situations are of regulatory interest because they may be associated with potentially significant dose consequences. The standard reference models from generic assessments are not able to address detailed processes related to site-specific issues [7].

\section{METHODOLOGY}

The planned repository for spent fuel at Forsmark on the eastern Baltic coast of Sweden, is to be constructed at around $500 \mathrm{~m}$ depth in the crystalline bedrock. Any transport and release of radionuclides from the repository will occur via the fracture network with discharges to local topographic minima [8]. The geosphere-biosphere interface at Forsmark is thin and highly variable in thickness and composition. The previous glaciation removed surface deposits down to the bedrock and the bulk of the "biosphere" comprises Quaternary Deposits (QD), laid down since the retreat of the ice. In the areas most likely to be associated with radionuclide release from the geosphere, the thickness of the QD is typically $3 \mathrm{~m}$.

The "biosphere" comprises surface water bodies (rivers, lakes, bays) and the upper $1 \mathrm{~m}$ of the QD. However, the role of the deeper QD has been of interest for some time [9] and we take this opportunity to provide additional model detail as suggested by [7], using three sets of calculations.

The first set of results illustrates accumulation in an evolving landscape where we model a $2 \mathrm{~m}$ column of the QD beneath river and wetland objects [5]. There are 20 layers, each $0.1 \mathrm{~m}$ thick with a net upwards flux of $0.058 \mathrm{~m} \mathrm{a}^{-1}$ [10]. In the river model, the upper three layers of the column $(30 \mathrm{~cm})$ represent river bed sediments with different characteristics compared to the otherwise homogeneous QD material [5]. Secondly, alternative interpretations of local hydrology are implemented using an advective-dispersive model for the $2 \mathrm{~m}$ wetland column (Figure 1a). Ten layers within each of which there are ten compartments (using the Ecolego Transport Block [4]). The same overall discharge as above is used but diffusion between the layers is also possible (diffusion coefficient $=0.0315 \mathrm{~m}^{2} \mathrm{a}^{-1}[11]$ ). Using the same advective/dispersive model we consider three cases: advection only, diffusion only with a zero concentration boundary condition at the top of the column, and, diffusion only with a zero-flux boundary condition across the upper boundary. Wetland parameters are taken 


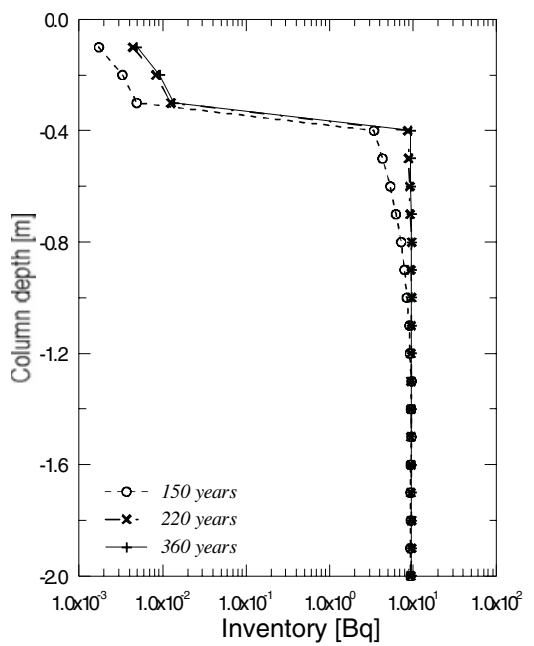

(a) QD beneath a river

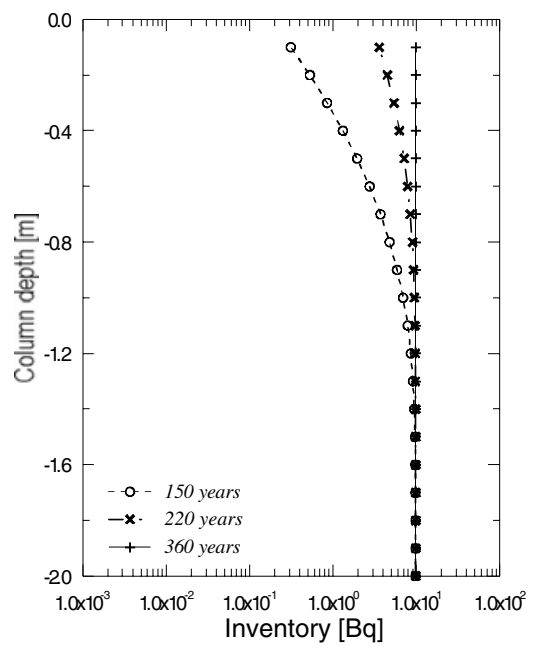

(b) QD beneath a wetland

Figure 2. Distribution of ${ }^{129} \mathrm{I}$ in the QD below a river and a wetland at three times.

from [12]. Finally, we investigate zonation in agricultural land using a ten-layer soil model (Figure 1b) with which doses are also evaluated. Emplaced drainage is assumed to be at a depth of $50 \mathrm{~cm}$. Below this layer the system has the characteristics of the original QD and is saturated. Above is a $30 \mathrm{~cm}$ variably saturated zone with a well drained surface layer of $30 \mathrm{~cm} \mathrm{[13].} \mathrm{We} \mathrm{use} \mathrm{a} \mathrm{revised} \mathrm{interpretation} \mathrm{of}$ bioturbation based on the model in [11]. Precipitation and evapotranspiration are, respectively, 0.558 and $0.410 \mathrm{~m} \mathrm{a}^{-1}$ [14]. An area of $10^{4} \mathrm{~m}^{2}$ is assumed [4]. Models are implemented in Ecolego [4, 5, 13].

We consider a chronic release of $1 \mathrm{~Bq} \mathrm{a}^{-1}$ each of ${ }^{129} \mathrm{I}$ and ${ }^{226} \mathrm{Ra}$ (daughters growing in for the dose calculations). $K_{d} \mathrm{~s}$ are taken from SR-Can for ${ }^{226} \mathrm{Ra}-2.0 \mathrm{~m}^{3} \mathrm{~kg}^{-1}[2,15]$. For ${ }^{129} \mathrm{I}$ more recent data are used [16] which distinguishes between $K_{d} \mathrm{~s}$ for anoxic/saturated and oxic/unsaturated conditions 0.004 and $0.03 \mathrm{~m}^{3} \mathrm{~kg}^{-1}$, respectively. The oxidising values are only used in the agricultural soil model but the SR-Can value for ${ }^{129} \mathrm{I}$ is also used to illustrate sensitivity in the advective/dispersive wetland model. The SR-Can value is $0.3 \mathrm{~m}^{3} \mathrm{a}^{-1}$ for organic soils $[2,15]$.

\section{RESULTS AND DISCUSSION}

Figure 2 shows the inventory of ${ }^{129} \mathrm{I}$ as a function of column depth at three times for release to each of river and wetland ecosystems. As modelled, equilibrium is reached after only 360 years due to the low $K_{d}$ of iodine in the saturated (anoxic) environment. The rapid mixing in the river bed sediment leads to lower concentrations in the upper layers of the model than in the case of wetland. On transition to full wetland conditions the main drainage channel moves away from its earlier location. In the wetland column there is a uniform distribution throughout by 360 years.

Conditions beneath wetlands in the Forsmark region are believed to have quite complex local hydrology [17] with net upwards and downwards vertical flow possible within the same landscape object. Mixing is primarily due to local meteoric flows. The interaction with the bedrock is poorly understood. The smaller the net upward flux, the greater the potential for accumulation [4]. At low advective flow rates the effects of diffusive fluxes need also to be considered. Diffusive transport (with alternate upper boundary conditions) is compared to advective transport in $3 \mathrm{a}$ for ${ }^{129} \mathrm{I}$ (which also looks at alternative $K_{d}$ values) and for ${ }^{226} \mathrm{Ra}$ in Figure $3 \mathrm{~b}$.

Accumulation over $9 \mathrm{ka}$ allows near-equilibrium distributions to come about and is typical of the timescale over which evolution of the landscape objects takes place. In the case of ${ }^{129}$ I the role of $K_{d}$ 


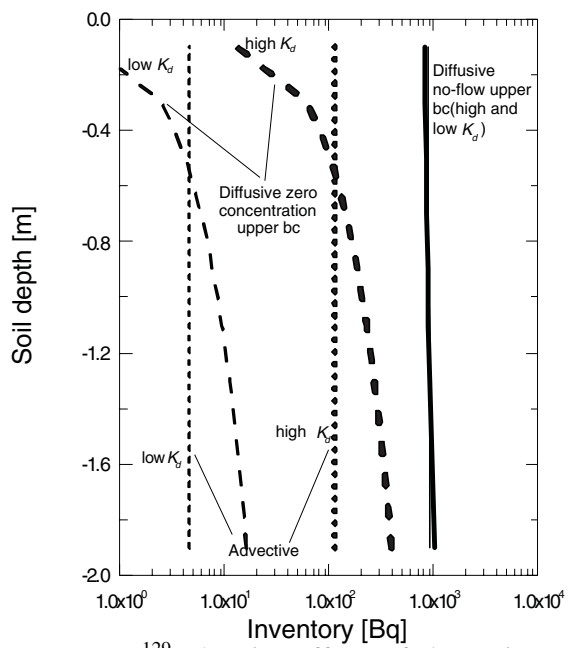

(a) ${ }^{129}$ I showing effects of alternative $K_{d} \mathrm{~s}$

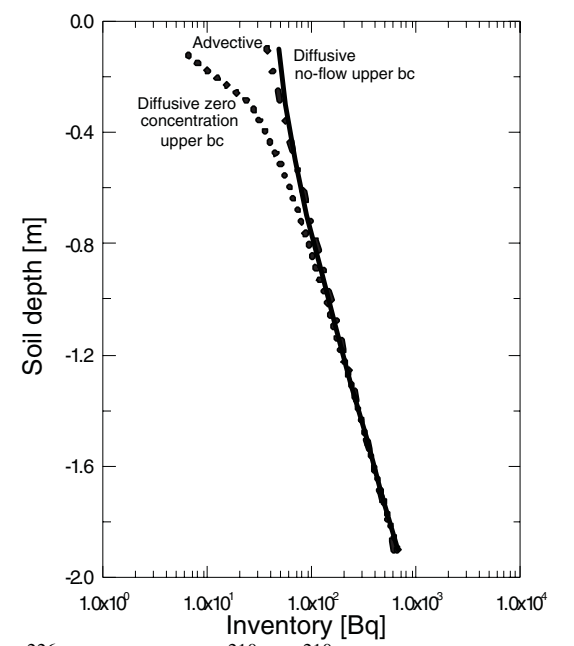

(b) ${ }^{226} \mathrm{Ra}$ (daughters ${ }^{210} \mathrm{~Pb},{ }^{210} \mathrm{Po}$ are in equilibrium)

Figure 3. Distributions of ${ }^{129} \mathrm{I}$ and ${ }^{226} \mathrm{Ra}$ in the wetland model at $9 \mathrm{ka}$ after the start of the release, assuming alternative hydrological conditions.

is clearly seen with the higher value leading to higher inventories in the case of both the advective flux and the diffusive flux with zero concentration at the upper boundary. The implicit loss at the upper boundary leads to a profile that varies with depth. When the advective flux dominates, a uniform profile results (cf. Figure 2). In situations where there is a no-flow boundary condition at the upper boundary (implicitly ruling out advective flows) there can be significantly higher accumulations in the profile and these arise irrespective of $K_{d}$. For the weakly sorbing ${ }^{129} \mathrm{I}$, a range of over two orders of magnitude is possible, depending on hydrology in the wetland. ${ }^{226} \mathrm{Ra}$ is more strongly sorbing and this has a dominant effect. Deeper in the profile the three alternatives give similar results. The zero-concentration boundary condition diffusive case has slightly lower inventories in the upper layers but the advective and no-flow boundary diffusive cases give similar results throughout.

The agricultural soil model is used to investigate geochemical zonation in the profile. Figure 4a demonstrates zonation effects caused by changes in redox conditions and different $K_{d} \mathrm{~s}$ in the different layers. The lower $40 \mathrm{~cm}$ is saturated and has the $K_{d}$ for reducing conditions. The upper $30 \mathrm{~cm}$ is clearly oxidising, mixing directly with meteoric input. Between is the variably saturated zone [13] for which we assume that the $K_{d}$ for oxic conditions is appropriate, leading to a step-change in the $K_{d}$ at $-0.6 \mathrm{~m}$. There is accumulation just above the transition zone with up to 8 times greater concentration between 50 and $60 \mathrm{~cm}$ depth. Similar patterns of zonation have been noted in lysimeter experiments (see page 211 of [18]) although the enhanced concentrations are less than reported here possibly because of the shorter timescale of the earlier experiments (upto 12 months). Results here suggest accumulation times will be upto one hundred years for the relatively low $K_{d} \mathrm{~s}$ assumed and the characteristics of the modelled column.

Doses in Figure $4 \mathrm{~b}$ are calculated on the basis of soil concentration using SKB's aggregated transfer factors [19]. Two sets of initial conditions are considered each with a continuing release of $1 \mathrm{~Bq} \mathrm{a}^{-1}$ to the base of the soil column: i. zero initial inventory in the column - simulating release to uncontaminated farmland, and ii. an initial distribution in the soil column derived from prior accumulation in the wetland column, corresponding to agricultural land cultivated an already contaminated drained wetland.

With zero initial inventory doses reach equilibrium after around $1 \mathrm{ka}$. With prior accumulation, there is an immediate higher dose which decreases slowly as the contaminants leach from the system. For the wetland model assumed here there can be around an order of magnitude increase in radiological impact 


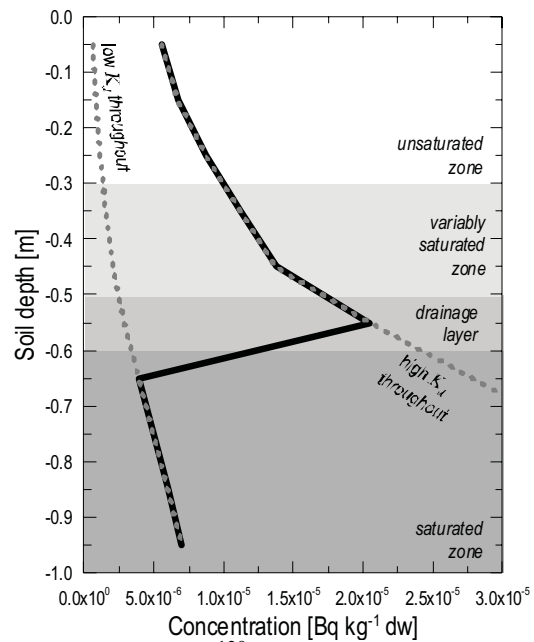

(a) Soil profiles for ${ }^{129} \mathrm{I}$, illustrating geochemical zonation effects, no prior accumulation.

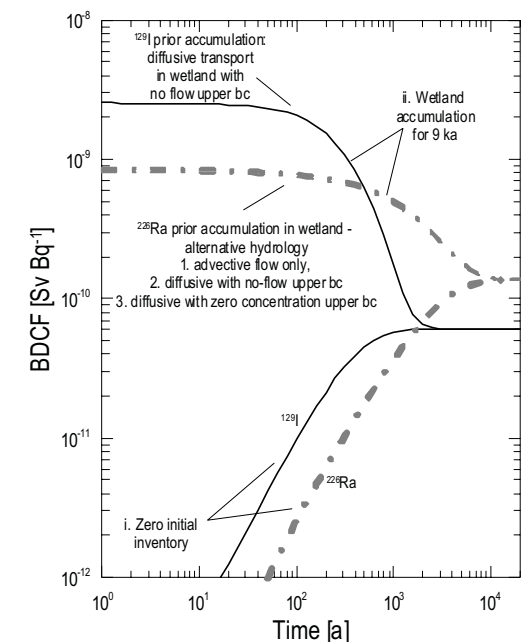

(b) Doses from agricultural land: i. no initial inventory and ii. wetland accumulations at 9 ka uniformly distributed at time $t=0$.

Figure 4. Results from the agricultural land model showing profile of ${ }^{129} \mathrm{I}$ at equilibrium distribution and doses arising from agricultural pathways using SKB's aggregated transfer coefficients [19].

for the ${ }^{226} \mathrm{Ra}$ chain and, potentially almost two orders of magnitude for ${ }^{129} \mathrm{I}$. Because both sets of initial conditions have chronic input, they both tend to the same long-term equilibrium value when the initial inventories have been leached away.

\section{CONCLUSIONS}

The models considered here offer a preliminary review of the mechanisms which increase doses over and above the results from standard generic biosphere models. The models describe pathways that are consistent with a 3D view of transport through both geosphere and biosphere, as well as taking into account spatial heterogeneity within the upper QD. Any such mechanisms are likely to be highly site specific (eg, high water table and wetland draining for cultivation) and so should be approached on a site-by-site basis.

Using a ten layer soil model, hydrogeochemical zonation has been shown to be relevant for ${ }^{129} \mathrm{I}$, the database for which has relatively low $K_{d}$ s. Clearly the effect would be greater were there to be a greater difference between reducing and oxidising $K_{d}$. The analysis also needs to be extended to other redox sensitive radionuclides $\left({ }^{79} \mathrm{Se},{ }^{99} \mathrm{Tc}\right.$, etc). However current databases (eg [20]) do not distinguish between redox conditions. This is an area which requires attention from experimentalists.

We note that prior accumulation is important in the rapidly evolving Swedish landscape. A greater understanding of the dynamics of potential release locations is important. Is it possible for accumulation times of $10 \mathrm{ka}, 100 \mathrm{ka}$ to arise, perhaps associated with permafrost? Lake/Wetland systems persist for perhaps $10 \mathrm{ka}$ and, for the more strongly sorbing radionuclides, this is barely sufficient for the modelled system to come into dynamic equilibrium. The higher the $K_{d}$, the greater the accumulation at depth. Mechanisms which would remove surface layers but leave intact deeper accumulations of activity in areas for subsequent cultivation are therefore also of interest.

In the modelling carried out here we have considered zero advective flow rates as one alternative. There is a need for a clearer understanding of the circulation of groundwater in the upper QD on spatial scales of a few metres to a few tens of metres. Only in this way will the interaction of the groundwater 
discharge from the fractured bedrock with the "biosphere" be a useful representation of reality. Given the potential for higher accumulation in the case of diffusive no-flow boundary conditions the scope for such situations to exist in potential future landscapes should be reviewed.

This final point questions the decoupling of geosphere and biosphere in mature performance assessments. In the diffusive release scenarios considered here we have assumed the standard input of $1 \mathrm{~Bq} \mathrm{a}^{-1}$ commonly used to define biosphere dose conversion factors. This interpretation is unrealistic and an integrated model of the geosphere-biosphere interface zone should be developed.

\section{References}

[1] IAEA, 'Reference Biospheres' for solid radioactive waste disposal: Report of BIOMASS Theme 1. IAEA-BIOMASS-6, (IAEA, Vienna, 2003).

[2] SKB,. Long-term safety for KBS-3 repositories at Forsmark and Laxemar - a first evaluation, SKB Technical Report TR-06-09, (Svensk Kärnbränslehantering, Stockholm, 2006).

[3] Karlsson, S, Bergström, U \& Meili, M, Models for dose assessments - models adapted to the SFRarea, SKB Technical Report TR-01-04 (Svensk Kärnbränslehantering AB, Stockholm, 2001).

[4] Kłos, R A., GEMA3D - landscape modelling for dose assessments, SSM report 2010:28 (Strålsäkerhetsmyndigheten, Stockholm, 2010).

[5] Broed, R \& Xu, S. Ecolego and AMBER Intercomparisons - testing capabilities in probabilistic calculations and sensitivity analyses, (Strål säkerhets myndigheten, Stockholm, in preparation).

[6] Xu S., Wörman A., Dverstorp B., Kłos, R. A., Shaw, G and Marklund, L., SSI's independent consequence calculations in support of the regulatory review the SR-Can safety assessment. SSI Report 2008:08 (Statens strålskyddsinstitut, Stockholm 2008).

[7] Kirchner, G. Use of Reference Biospheres for Proving the Long-Term Safety of Radioactive Waste Repositories, J. Environ. Radioactivity 100 (2009) 435 - 437.

[8] Marklund, L., Wörman, A., Geier, J., Simić, E., \& Dverstorp, B., Impact of landscape topography and quaternary overburden on the performance of a geological repository of nuclear waste. Nuclear Technology, 163 (2008) pp. 165-179.

[9] Wörman, A., Dverstorp, B., Kłos, R. A., Xu, S., Role of the Bio- and Geosphere Interface on Migration Pathways for Radionuclides and Ecological Effects. Nuclear Technology, 148, (2004), pp. 194 - 204.

[10] SKB, The biosphere at Laxemar. Data, assumptions and models used in the SR-Can. Stockholm, SKB Report. R-06-83, (Svensk Kärnbränslehantering, Stockholm, 2006).

[11] Jarvis, N. J., Taylor, A., Larsbo, M., Etana, A., \& Rosén, K., Modelling the effects of bioturbation on the re-distribution of 137Cs in an undisturbed grassland soil. European Journal of Soil Science. 61, (2010), pp. 24-34.

[12] Kellner, E., Wetlands - different types, their properties and functions, SKB Technical Report. TR-04-08 (Svensk Kärnbränslehantering, Stockholm, 2003).

[13] Kłos, R. A., Limer, L. \& Shaw, G., Advanced Biosphere Modelling for Safety Assessment, 2010, Project Report ASN-10-03 (Aleksandria Sciences, Sheffield, 2011).

[14] Johansson, P-C, \& Öhman, J., Presentation of meteorological, hydrological and hydrogeological monitoring data from Forsmark Site descriptive modelling: SDM-Site Forsmark, SKB Report R-08-10 (Svensk Kärnbränslehantering, Stockholm, 2010).

[15] Karlsson, S. \& Bergström, U., Nuclide documentation: Element specific parameter values used in the biospheric models of the safety assessments SR 97 and SAFE, SKB Report R-02-28 (Svensk Kärnbränslehantering, Stockholm, 2010).

[16] Maillant, S., Sheppard, M. I., Echevarria, G., Denys, S., Villemin, G., Tekely, P., Leclerc-Cessac, E., \& Morel, J L., Aged anthropogenic iodine in a boreal peat bog, Applied Geochemistry, 22, (2007) pp. 873-887. 
[17] Vikström, M. \& Gustafsson, L-G., Modelling transport of wetlands and solutes in future wetlands in Forsmark, SKB Report. R-06-46 (Svensk Kärnbränslehantering, Stockholm, 2010).

[18] Wheater, H.S., Bell, J.N.B., Butler, A.P., Jackson, B.M., Ciciani, L., Ashworth, D.J. Shaw, G.G., Biosphere implications of deep disposal of nuclear waste: the upwards migration of radionuclides in vegetated soils, (Imperial College Press, London, 2007).

[19] Avila, R., Ekström, P-A, \& Kautsky, U., Development of landscape dose factors for assessments in SR-Can, SKB Technical Report. TR-06-15 (Svensk Kärnbränslehantering, Stockholm, 2010).

[20] IAEA. Quantification of Radionuclide Transfer in terrestrial and Freshwater Environments for Radiological Assessments, IAEA TecDoc 1616, (IAEA, Vienna, 2009). 